\title{
Tracheal Mucormycosis Pneumonia: A Rare Clinical Presentation
}

\author{
Satyawati Mohindra MS DNB, Bhumika Gupta MS DNB, \\ Karan Gupta MS, and Amanjit Bal MD
}

\begin{abstract}
This article reports an unusual case of tracheal mucormycosis following H1N1 pneumonia and reviews previously reported cases. A 40-y-old female with a 5-y history of diabetes mellitus, adequately controlled by oral hypoglycemic agents, developed tracheal mucormycosis after successful treatment for H1N1 pneumonia. The condition was diagnosed during workup for decannulation due to subglottic and upper tracheal obstruction by necrotic chewing gum-like tissue and cartilage. The patient was managed successfully by treatment with amphotericin $B$ and surgical intervention in the form of laryngofissure and Montgomery tube placement. A review of the literature revealed only 5 previously reported cases of tracheal mucormycosis. A high degree of suspicion, early endoscopy and biopsy, histopathological evidence of the infection, and early institution of therapy are the keys to successful outcome. Key words: tracheal mucormycosis; H1N1 pneumonia; Montgomery tube. [Respir Care 2014;59(11):e178-e181. (C) 2014 Daedalus Enterprises]
\end{abstract}

\section{Introduction}

Mucormycosis is the third most common invasive fungal infection after candidiasis and aspergillosis. It is an important opportunistic infection, caused by fungus that belongs to the order Mucorales. ${ }^{1}$ Members of the genera Rhizopus, Mucor, Absidia, and Rhizomucor are the Mucorales most commonly isolated from patients. Cunninghamella, Apophysomyces, and Saksenaea have occasionally been implicated in human diseases, sometimes even in immunocompetent patients. Predisposing factors are diabetes mellitus with or without ketoacidosis, organ transplantation, bone marrow aplasia, COPD with low-dose steroids, and desferroxamine therapy for iron overload.

Drs Mohindra, Gupta, and Gupta are affiliated with the Department of Otolaryngology and Head-Neck Surgery, and Dr Bal is affiliated with the Department of Histopathology, Postgraduate Institute of Medical Education and Research, Chandigarh, India.

The authors have disclosed no conflicts of interest.

Correspondence: Karan Gupta MS, Department of Otolaryngology and Head-Neck Surgery, Postgraduate Institute of Medical Education and Research, Chandigarh 160012, India. E-mail: karan_gupta86@ yahoo.com.

DOI: $10.4187 /$ respcare. 03174
Mucormycosis can present in any form: rhinocerebral, pulmonary, intestinal, disseminated, and cutaneous. Mucorales rarely invades the trachea and tracheal cartilage. ${ }^{1}$

Herein, we report an unusual case of tracheal mucormycosis in a diabetic female patient treated for H1N1 pneumonia. The relevant literature has been reviewed.

\section{Case Report}

A 40-y-old female with a 5-y history of type II diabetes, managed by oral hypoglycemic agents, presented to the pulmonology department of our institute with fever, cough, generalized malaise, and stridor for $10 \mathrm{~d}$. On examination, she was drowsy, tachypneic, and tachycardic. Bilateral rhonchi and crepitations were present. Polymerase chain reaction for influenza type A H1N1 was positive in nasopharyngeal swab, and the patient was managed with oxygen, antibiotics, Tamiflu (oseltamivir), and bronchodilators. During the initial management, she developed stridor, for which a tracheostomy was performed. After 1 month, the patient was referred to the otolaryngology out-patient department for decannulation. During evaluation for the same, computed tomography of the neck revealed soft tissue density filling the subglottis and upper trachea, along with the presence of necrosed and fragmented cricoid cartilage (Fig. 1A). After admission, endoscopic assessment revealed necrotic tissue of chewing gum consistency and 

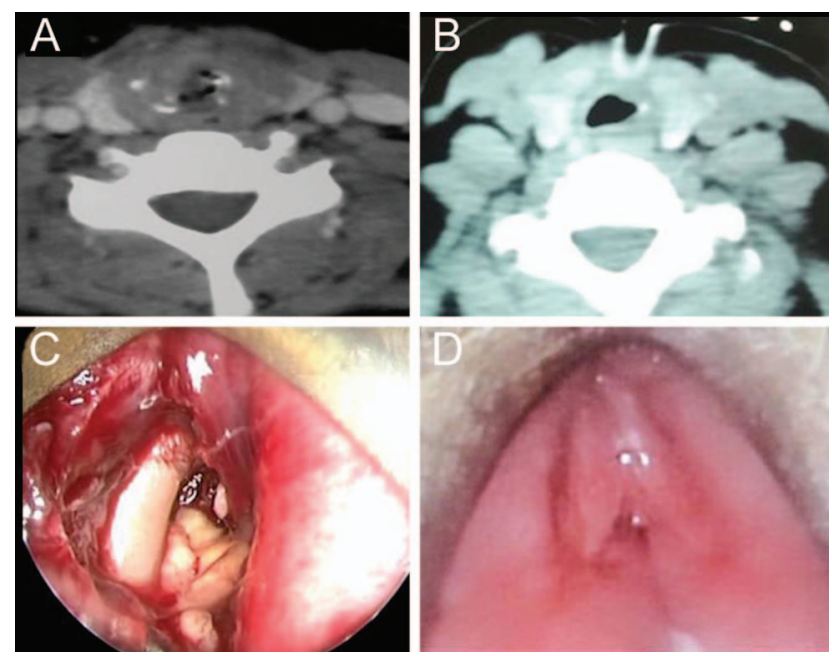

Fig. 1. A: Pre-amphotericin B (AmB) contrast-enhanced computed tomogram (CT) of the neck (axial section) showing soft tissue in the upper trachea. Fragmented cartilage can also be seen. B: Post-AmB contrast-enhanced CT of the neck (axial section) showing a better airway. Some mucosal edema is still persistent. C: Endoscopic photograph at the same time showing bare cartilage and chewing gum-like tissue almost completely blocking the subglottis and upper trachea. D: Post-AmB endoscopic photograph showing edematous and partially opposed false cords, but the necrotic tissue is absent.

exposed cartilage in subglottis and upper trachea (see Fig. 1C). Edematous arytenoids and false cord were also seen. Histopathology was suggestive of mucormycosis with broad, aseptate hyphae (Fig. 2A). A non-contrast computed tomography scan of nose and paranasal sinuses was done to rule out any primary focus of infection (see Fig. 2B). On day 4 after admission, the patient was started on amphotericin $\mathrm{B}(\mathrm{AmB})$ injection. After giving a test dose of amphotericin, $50 \mathrm{mg}$ of conventional $\mathrm{AmB}$ was given daily. However, after $4 \mathrm{~d}$ of therapy, the patient developed severe hypokalemia (serum $\mathrm{K}^{+}=2.9 \mathrm{mEq} / \mathrm{L}$ ), which was corrected by giving intravenous potassium $\left(\mathrm{K}^{+}\right)$supplementation. Once normal $\mathrm{K}^{+}$levels were achieved, the patient was switched to liposomal AmB. After completing $2,500 \mathrm{mg}$ on day 32 , repeat computed tomography showed a better airway lumen, and endoscopy revealed healthylooking false cords, which were partially opposed to each other by fibrous tissue (see Fig. 1D). Necrotic slough was absent. The subglottis was partially occluded with fibrous tissue before tracheostomy. Biopsy from the tissue was negative for fungus. Subsequently, the patient underwent a laryngofissure and Montgomery tube insertion under general anesthesia to establish and dilate the airway and for rehabilitation of speech (see Fig. 2C and D). Necrotic cricoid cartilage and surrounding fibrous tissue were removed. Postoperatively, AmB injection was continued up

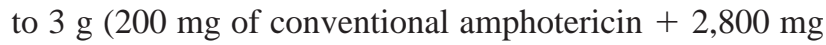
of liposomal AmB). Throughout the treatment, blood sugar
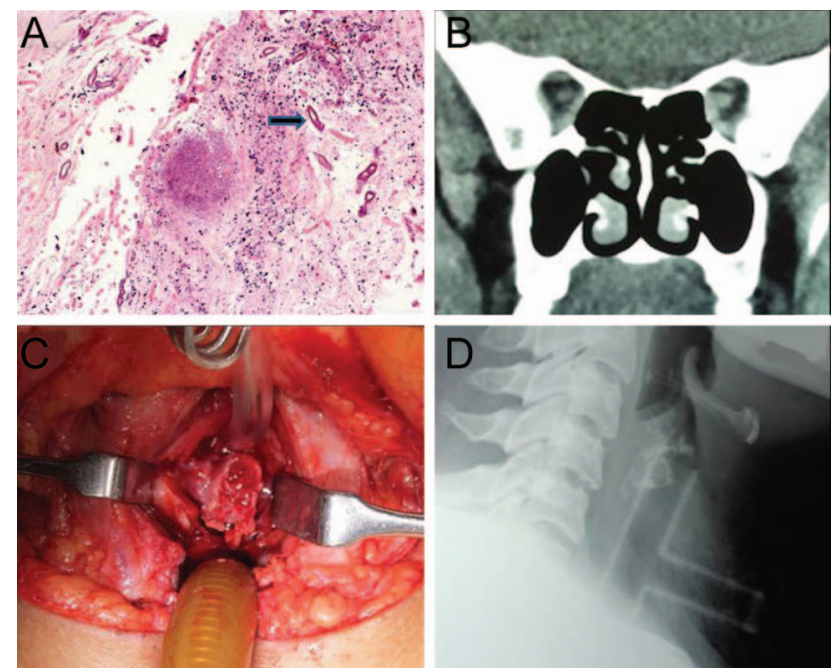

Fig. 2. A: Photomicrograph showing broad aseptate fungal hyphae (arrow) conforming to morphology of mucormycosis in a necrotic background (hematoxylin and eosin stain, magnification $\times 200$ ). B: Non-contrast-enhanced computed tomogram (CT) of nose and paranasal sinuses. Coronal section done to rule out a primary source of infection does not show any evidence of soft tissue density suggestive of fungal pathology. C: Intra-operative view through a laryngofissure showing necrotic cartilage surrounded by fibrous tissue. D: Roentgenogram of neck (lateral view) showing the placement of a Montgomery tube, thereby dilating the suprastomal area and providing an airway through the tracheostomy limb.

levels were well controlled with insulin injection. Patient is doing well at 4 months of follow-up.

\section{Discussion}

Mucormycosis is a life-threatening, opportunistic disease caused by fungi belonging to the order Mucorales. ${ }^{1}$ Mucorales cause a deep tissue infection and angio-invasion. In pulmonary mucormycosis, the spores are inhaled, resulting in colonization with spread through the bronchial wall to invade blood vessels, especially arterioles, producing degrees of frank ischemia, hemorrhagic infarction, and tissue necrosis. Mucormycosis is usually seen in diabetic patients with or without ketoacidosis or in patients with other risk factors, including cancer (such as leukemia, lymphoma, multiple myeloma, etc.), AIDS, chemotherapy, organ transplantation, anti-rejection treatment, iron chelate treatment, severe malnutrition, and the application of broadspectrum antibiotics. ${ }^{1}$

Pulmonary mucormycosis is difficult to diagnose because presentation is similar to bacterial infection with fever, cough, expectoration, hemoptysis, and pleuritic chest pain. The prominent finding is bilateral pulmonary fixed rales or pleural rubs. There is airway obstruction and voice change when Mucorales invade the trachea and larynx. Lee et $\mathrm{al}^{2}$ reported 87 patients with localized pulmonary 
Table 1. Previously Reported Cases of Tracheal Mucormycosis

\begin{tabular}{|c|c|c|c|c|c|c|}
\hline Authors & $\begin{array}{c}\text { Subject } \\
\text { Age }(y), \text { Sex }\end{array}$ & Comorbidity & $\begin{array}{c}\text { Segment of } \\
\text { Trachea Involved }\end{array}$ & $\begin{array}{l}\text { Endoscopic } \\
\text { Appearance }\end{array}$ & $\begin{array}{l}\text { Amphotericin/ } \\
\text { Other }\end{array}$ & Outcome \\
\hline Schwartz et al ${ }^{4}$ & 20 , female & $\begin{array}{l}\text { Diabetic } \\
\quad \text { ketoacidosis }\end{array}$ & $\begin{array}{l}\text { Larynx and upper } 5 \\
\text { tracheal rings }\end{array}$ & $\begin{array}{l}\text { Edematous } \\
\text { laryngotracheal } \\
\text { mucosa }\end{array}$ & $5-25 \mathrm{mg} / \mathrm{d}$ & Well at 24 mo \\
\hline Andrews et $\mathrm{al}^{5}$ & 75 , male & $\begin{array}{l}\text { Diabetic } \\
\text { ketoacidosis }\end{array}$ & Lower trachea & $\begin{array}{r}\text { Chewing gum } \\
\text { consistency }\end{array}$ & Not mentioned & $\begin{array}{l}\text { Died of bacterial } \\
\text { pneumonia }\end{array}$ \\
\hline Wolf et $\mathrm{al}^{6}$ & 61 , male & $\begin{array}{l}\text { Diabetic } \\
\text { ketoacidosis }\end{array}$ & Upper and mid trachea & $\begin{array}{l}\text { Greyish mass; } \\
\text { chewing gum } \\
\text { consistency }\end{array}$ & $\begin{array}{l}1.2 \mathrm{mg} / \mathrm{kg} / \mathrm{d} \text { for } 6 \mathrm{wk} \text { and } \\
\text { resection of trachea }\end{array}$ & Tracheostomy at $9 \mathrm{mo}$ \\
\hline $\begin{array}{l}\text { Hashemzadeh } \\
\text { et } \mathrm{al}^{7}\end{array}$ & 24 , male & $\begin{array}{l}\text { ALL on } \\
\text { induction } \\
\text { chemotherapy }\end{array}$ & $\begin{array}{l}\text { Mycotic aneurysm of } \\
\text { RCCA with tracheal } \\
\text { involvement }\end{array}$ & Not mentioned & $\begin{array}{l}\text { 1-g cumulative dose and } \\
\text { resection of anastomotic } \\
\text { segment }\end{array}$ & $\begin{array}{l}\text { Well but with tracheal } \\
\text { narrowing at } 24 \text { mo }\end{array}$ \\
\hline Luo et $\mathrm{al}^{8}$ & 46 , male & Diabetic & Upper trachea & $\begin{array}{l}\text { Cricoid involved } \\
\text { and tumor-like } \\
\text { mass }\end{array}$ & $\begin{array}{l}1.8875 \mathrm{~g} \text { of conventional } \\
\mathrm{AmB}, 4 \mathrm{~g} \text { of liposomal } \\
\mathrm{AmB}\end{array}$ & Well at 2 mo \\
\hline Present report & 40 , female & $\begin{array}{l}\text { Diabetic } \\
\text { H1N1 } \\
\text { pneumonia }\end{array}$ & Upper trachea & $\begin{array}{l}\text { Cricoid involved } \\
\text { and necrotic } \\
\text { chewing gum- } \\
\text { like tissue }\end{array}$ & $\begin{array}{l}200 \mathrm{mg} \text { of conventional } \\
\mathrm{AmB}, 2,800 \mathrm{mg} \text { of } \\
\text { liposomal } \mathrm{AmB}(3 \mathrm{~g} \\
\text { cumulative) }\end{array}$ & $\begin{array}{l}\text { Well at } 4 \text { mo with } \\
\text { M-tube in situ }\end{array}$ \\
\hline \multicolumn{7}{|c|}{$\begin{array}{l}\text { ALL = acute lymphoblastic leukemia } \\
\text { RCCA = right common carotid artery } \\
\text { AmB = amphotericin B } \\
\text { M-tube = Montgomery tube }\end{array}$} \\
\hline
\end{tabular}

mucormycosis. Of these, 34 had evidence of visible endobronchial disease. Rigid bronchoscopy appears to be a diagnostic modality of choice in major airway involvement and may reveal granulation tissue and gray-white mucoid material. Involved airways are typically edematous and necrotic. Invasive fungal infection can also present as an endobronchial mass. ${ }^{3}$

Simultaneous tracheal and laryngeal cartilage damage can occur. ${ }^{3}$ Isolated tracheal mucormycosis is very rare (Table 1). Anand et $\mathrm{al}^{9}$ presented a case of laryngeal mucormycosis limited to vocal cords as a vocal polyp. Only 5 cases of isolated tracheal mucormycosis could be found after a thorough search of the world literature (Table 1). One of the patients also had a mycotic aneurysm of the right common carotid artery. ${ }^{7}$ Four of 5 patients were male, and only 1 was female (excluding our case). Diabetes mellitus was the most common association. H1N1 pneumonia association has not been reported until now. To date, the association of invasive pulmonary aspergillosis has been studied with $\mathrm{H} 1 \mathrm{~N} 1$ pneumonia, with up to $23 \%$ of critically ill patients with H1N1 pneumonia found to be suffering from invasive pulmonary aspergillosis in a study by Wauters et al. ${ }^{10}$

Rigid bronchoscopy frequently shows necrotic tissue and cartilage. We did not remove the protruding cartilage, as we could see transmitted pulsations. Cartilage can sometimes be expectorated spontaneously. ${ }^{11}$ Histopathology confirms the diagnosis. Specimen can be collected by endoscopic biopsy, percutaneous needle biopsy, or open lung biopsy, all of which show tissue invasion with characteristic broad, aseptate hyphae with right-angle branching. ${ }^{4}$ In our case, the diagnosis was also confirmed by histopathological evidence of broad, aseptate hyphae.

Early diagnosis and antifungal therapy are the major determinants of final outcome. ${ }^{4,6,8}$ Surgery plays a role in debulking of the disease. Among antifungal agents, AmB is the treatment of choice. It is given in a dose of 1-1.5 $\mathrm{mg} / \mathrm{kg}$. Patients should be monitored for renal function and serum electrolytes, especially serum potassium. ${ }^{12,13}$ Liposomal AmB can be given in cases with compromised renal function and hypokalemia. Prolonged duration of treatment with $\mathrm{AmB}$ is one of the major reasons for discontinuation and incomplete treatment of patients with fungal disease. The azole group of drugs are not considered to be effective in mucormycosis. However, a newer agent, posaconazole, is thought to be effective against mucormycosis. Some cases were successfully treated with posaconazole alone, especially in post-transplant diabetic patients where AmB had failed or was contraindicated due to renal failure. ${ }^{13}$ In our case, treatment was started with conventional AmB, but, due to its adverse renal effects, was switched to liposomal AmB. Outcomes were successful for all the patients who were treated with amphotericin. The lone mortality among the cases we reviewed is the patient who was unable to begin treatment with amphotericin, due to poor general condition. ${ }^{5}$

Endolaryngeal and endotracheal involvement is more difficult to manage. A negative biopsy is not the end point. 


\section{Tracheal Mucormycosis Pneumonia}

Usually, the airway becomes narrowed and needs active intervention. In the past, resection anastomosis has also been carried out for the same. ${ }^{6}$ Our patient was experiencing upper tracheal involvement with edematous mucosa in the larynx and subglottis. Anastomosis was unlikely to be successful. We inserted a Montgomery tube via laryngofissure. Using this method, we could excise all the offending tissue and place a Montgomery tube, which served dual functions of dilating the suprastomal airway and at the same time acting as a tracheostomy if required. Voice rehabilitation was also achieved.

High degree of suspicion, early endoscopy and biopsy, histopathological evidence of infection, and early institution of therapy are the keys to successful outcome.

\section{REFERENCES}

1. Aboutanos MB, Joshi M, Scalea TM. Isolated pulmonary mucormycosis in a patient with multiple injuries: a case presentation and review of the literature. J Trauma 2003;54(5):1016-1019.

2. Lee FY, Mossad SB, Adal KA. Pulmonary mucormycosis: the last 30 years. Arch Intern Med 1999;159(12):1301-1309.

3. Husari AW, Jensen WA, Kirsch CM, Campagna AC, Kagawa FT, Hamed KA, et al. Pulmonary mucormycosis presenting as an endobronchial lesion. Chest 1994;106(6):1889-1891.
4. Schwartz JR, Nagle MG, Elkins RC, Mohr JA. Mucormycosis of the trachea: an unusual cause of acute upper airway obstruction. Chest 1982;81(5):653-654.

5. Andrews DR, Allan A, Larbalestier RI. Tracheal mucormycosis. Ann Thorac Surg 1997;63(1):230-232.

6. Wolf O, Gil Z, Leider-Trejo L, Khafif A, Biderman P, Fliss DM. Tracheal mucormycosis presented as an intraluminal soft tissue mass. Head Neck 2004;26(6):541-543.

7. Hashemzadeh S, Tubbs RS, Fakhree MB, Shoja MM. Mucormycotic pseudoaneurysm of the common carotid artery with tracheal involvement. Mycoses 2008;51(4):347-351.

8. Luo LC, Cheng DY, Zhu H, Shu X, Chen WB. Inflammatory pseudotumoural endotracheal mucormycosis with cartilage damage. Eur Respir Rev 2009;18(113):186-189.

9. Anand CS, Gupta MC, Kothari MS, Anand TS, Singh SK. Laryngeal mucormycosis. Ind J Otolaryngol 1978;30(2):90-92.

10. Wauters J, Baar I, Meersseman P, Meersseman W, Dams K, De Paep R, Lagrou K, Wilmer A, Jorens P, Hermans G. Invasive pulmonary aspergillosis is a frequent complication of critically ill $\mathrm{H} 1 \mathrm{~N} 1 \mathrm{pa}-$ tients: a retrospective study. Intensive Care Med 2012;38(11):17611768.

11. Park MJ, Woo IS, Son JW, Lee SJ, Kim DG, Mo EK, et al. Endobronchial tuberculosis with expectoration of tracheal cartilages. Eur Respir J 2000;15(4):800-802.

12. Mohindra S, Mohindra S, Gupta R, Bakshi J, Gupta SK. Rhinocerebral mucormycosis: the disease spectrum in 27 patients. Mycoses 2007; 50(4):290-296

13. Greenberg RN, Scott LJ, Vaughn HH, Ribes JA. Zygomycosis (mucormycosis): emerging clinical importance and new treatments. Curr Opin Infect Dis 2004;17(6):517-525. 